\title{
Review of Conventional and Innovative Technologies for Fire Retrofitting of Existing Buildings
}

\author{
Farshad Zahmatkesh'1, Ali M. Memari² \\ ${ }^{1}$ The Pennsylvania Housing Research Center, Penn State University, University Park, PA, USA \\ ${ }^{2}$ Department of Architectural Engineering and Department of Civil and Environmental Engineering, Penn State University, \\ University Park, PA, USA \\ Email:fa_zahmatkesh@yahoo.com,memari@engr.psu.edu
}

How to cite this paper: Zahmatkesh, F. and Memari, A.M. (2017) Review of Conventional and Innovative Technologies for Fire Retrofitting of Existing Buildings. Open Journal of Civil Engineering, 7, 222-244. https://doi.org/10.4236/ojce.2017.72014

Received: February 3, 2017

Accepted: June 4, 2017

Published: June 7, 2017

Copyright $\odot 2017$ by authors and Scientific Research Publishing Inc. This work is licensed under the Creative Commons Attribution International License (CC BY 4.0).

http://creativecommons.org/licenses/by/4.0/

\begin{abstract}
Fire effects can be one of the most harmful conditions that any building may experience throughout its service life. Developing practical protection methods and concepts against potential fire disasters in buildings has been an important consideration in design of buildings in recent decades. Rapid developments in technology have heightened the demand for new and innovative fire protection systems in comparison with conventional and traditional methods. Such a need for new technologies is in particular of greater importance when it comes to existing buildings. Retrofitting an existing building for fire safety is a greater challenge compared with designing a new building using materials and components that have more desirable and superior fire rating to begin with. Furthermore, strategies to design a new building that includes state-of-the-art fire safety features are also different from solutions that may be more suitable for retrofitting an existing building. This paper presents a review of the literature concerning conventional and new or innovative retrofitting methods for fire safety of buildings. Advantages and disadvantages of different fire protection devices and methods as available and understood from the literature are mentioned. Study of fire safety systems shows that each has its drawbacks. Comparison of the results shows that disadvantages of a solitary system for retrofitting against fire can be improved by using a combination of several fire safety concepts or methods simultaneously.
\end{abstract}

\section{Keywords}

Fire Retrofitting, Fire Safety, Building Components, Conventional Method, Innovative Technology 


\section{Introduction}

The potential for residential fire disasters (Figure 1) is of great concern in building design and a significant factor in architectural design of buildings in terms of construction material, configuration, openings and emergency exit strategy. One of the most critical aspects of a building is structural behavior of load-bearing and non-load bearing components under fire and high temperature loading conditions, which can lead to loss of load carrying capacity and thus instability. Providing suitable methods for protection of building components during fires has always been a challenging topic for engineers. Therefore, fire safety systems can play a key role in prevention control or relief of fire before serious damage is incurred to the main components of a building. Needless to say, without proper safety and protection measures, various damage ranges, high repair costs, and even injury or deaths may follow.

As many cities experience shortage of land for more residential and commercial construction due to population growth and migration in modern societies, in particular in metropolitan areas, it is inevitable that building with larger number of stories will be needed, but that will also lead to higher risk of fire hazard. The potential for fire incidents in multi-story apartment buildings remains a serious concern for local governments, municipalities, and building owners/tenants. Karter [1] studied fire losses in the US during 2012 and found that the Fire Departments across the country reported around 1,375,000 fire incidents during that particular year. The Fire Department reports indicate that fire incidents caused over $\$ 12$ billion property damage, 16,500 injuries and 2855 deaths. Karter study [1] also shows that the risk of fire incidents in residential buildings is much more than other cases such that $83 \%$ of fire-related fatalities occurred in homes. As an example of such hazards in overpopulated societies, an official report of China Fire Services shows that about $40 \%$ of fire incidents occurred in residential buildings [2] [3] [4] [5] [6]. Because of the expected long life-span of existing buildings, the most reasonable strategy to minimize consequences of fire occurrences seems to be focusing on developing measures for

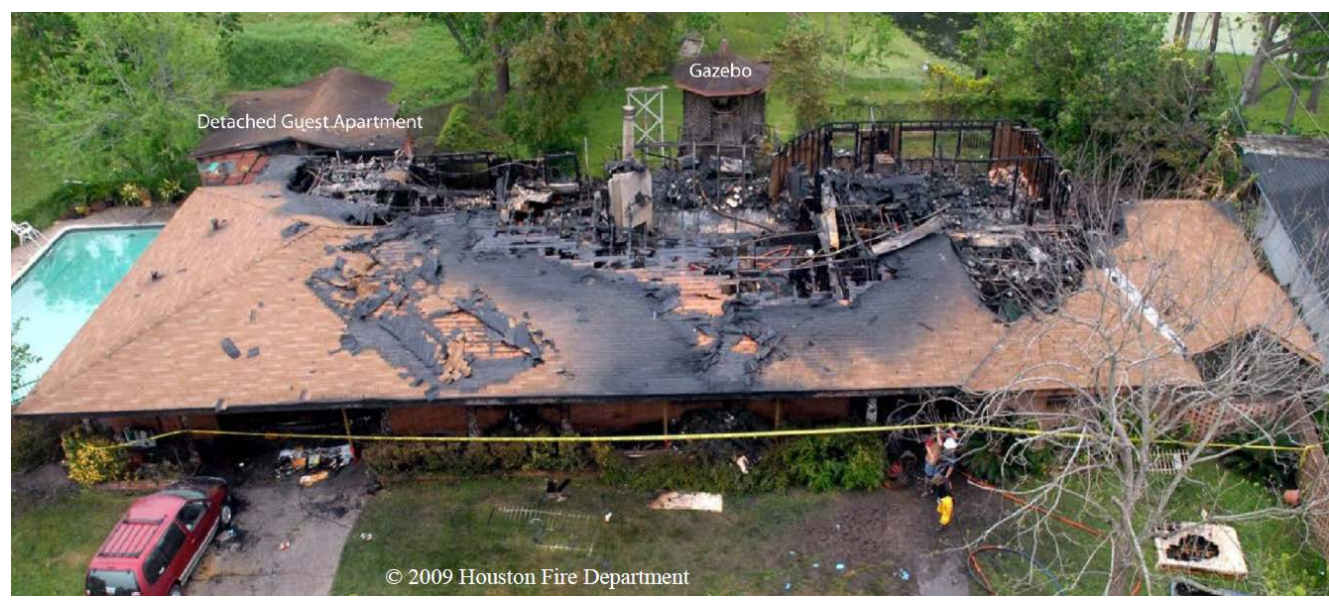

Figure 1. Example fire damage to a residential building (Courtesy of NIST Technical Note 1729; http://ws680.nist.gov/publication/get_pdf.cfm?pub_id=909779). 
existing and older buildings in large cities. Moreover, in some cases because modern urban landscape would require long distance transportation of the workforce between home and workplace, some building use changes may be inevitable. These modifications may include the need to have commercial and residential buildings be physically closer and even there may be a need to change the use of buildings, e.g., change the use from commercial to residential or allow mixed use, etc.

These building use changes may trigger and involve required upgrades by building codes. One of the most critical aspects of these upgrades is fire safety, a key aspect of which in these buildings is to ensure that the building's fire protection systems (if any) function properly. In particular, the traditional fire protection systems require special attention to meet performance standards and code compliance. Creating a comprehensive plan for inspection, testing, and maintenance of these systems can help reduce risk and improve chances of success of the system's performance. Study of fire safety performance of older buildings in terms of fire spread may lead to selection of different fire safety strategy options [7], and inspection and maintenance of fire protection devices [8].

Buildings are usually designed and constructed based on building codes' fire safety provisions. Such provisions generally provide some standards and the commentaries offer guidelines and concepts for fire alarm and safety such as smoke detector, fire alarm installations, sprinkler systems and fire extinguishers in new buildings. Although new buildings are generally constructed by using more advanced and modern structural and nonstructural systems per building code requirements and industry products, the building contents may not necessarily have been developed and manufactured with consideration of fire safety criteria. This means that because of ever increasing use of modern electronic devices, furniture and various combustible materials and components in buildings, the possibility of fire incidents likely increases [9] [10] [11] [12] [13]. The problem is likely more serious in older dwellings and homes that have amassed large volumes of vulnerable content. Therefore, one of the most significant current problems is fire safety of existing and older buildings since most of these buildings may not fully satisfy the fire safety requirements.

In recent years, engineers have employed some retrofitting methods to reduce the fire hazards. Most studies on fire safety of buildings have focused only on evaluation of new buildings based on fire safety provisions of building codes [14] [15] [16] [17]. With every change of use, change of occupancy, or change of story height, fire protection requirements need to be evaluated. Although retrofit projects have been carried out on fire safety of historical and old buildings [18] [19], limited information on comparison, advantages and disadvantages of various fire retrofitting systems is available. To have a better understanding of various retrofitting methods, there is a need for a thorough review of literature related to fire hazards. Such a study can then lead to evaluation of various options and determining appropriateness of solutions for different situations. 


\section{Review of Fire Incidents in Existing Buildings}

One of the most significant current discussions in mitigation of fire hazards is retrofit of existing buildings. For instance, when changes are to be made in a building, usually upgrading or adding fire protection systems will also be part of the change. In this regard, to find the most suitable retrofitting method, learning from past fire incidents in similar buildings will be useful. This section reviews some example reported fire incidents to help better understanding of the common causes of fire spread in the existing buildings. Generally, any proposed method for retrofitting existing buildings should be based on a sound understanding of causes of fire incidents and its spread. For example, on May 22, 2010, a fire incident was reported to the US. Fire Administration office in Kansas [20]. An automatic fire alarm was received at 20:52 from the residence. The incident involved a 6000 square foot two-story single-family residence with a full-basement that was built in 1998. The lower level included a walk-out basement (Figure 2). The main floor consisted of a great room, dining room, kitchen, breakfast room, master bedroom and bath with make-up room, utility room, office and a two car garage. The top floor consisted of three bedrooms and two full bath-rooms. After the fire incident, the office of the State Fire Marshal reported that the building was not equipped with a proper fire sprinkler system. The firefighting time table in Figure 2 shows that despite a quick automatic fire alarm, lack of an adequate fire sprinkler system can lead to a significant damage to the whole building.

As a second example, one can cite the fire incident reported on March 8, 2015 when a Danville man escaped unharmed from a fire that destroyed his home in the evening [McGee 2015, News-Gazette 4/28/2015]. Firefighters were called to a house fire around 6 p.m. When they arrived, heavy fire and smoke was coming from the front of the small, one-story, wood-frame structure. The report shows that the house occupant was asleep on his couch when the fire broke out, but was awakened by the smell of smoke to see his kitchen was on fire. He was not injured and firefighters extinguished the fire in about 20 minutes. According to the firefighters, the fire caused the front of the house and roof to cave in, which caused an estimated $\$ 25,000$ damage. This report indicates that there was no fire extinguisher and alarm system at the home, and the occupant was awakened by the smell of the smoke. Perhaps, if there was a smoke detector or fire alarm, the occupant could wake up sooner. Also, the existence of a fire extinguisher system such as fire blanket and sprinkler in the kitchen could help extinguishing the fire or to prevent its spread.

A fire incident was reported in a residential building in Peekskill-Cortland, NY that was extinguished by the assistance of Lake Mohegan Volunteer Fire Association [21]. The report shows that this building was not equipped with an adequate fire safety system. Despite key role of the fire alarm and fire sprinkler systems in fire incidents, the use of fireproof materials and components is always a reliable strategy to protect against or delay fast fire spread to other places in a building. The report indicates that unprotected openings in the building envelope 


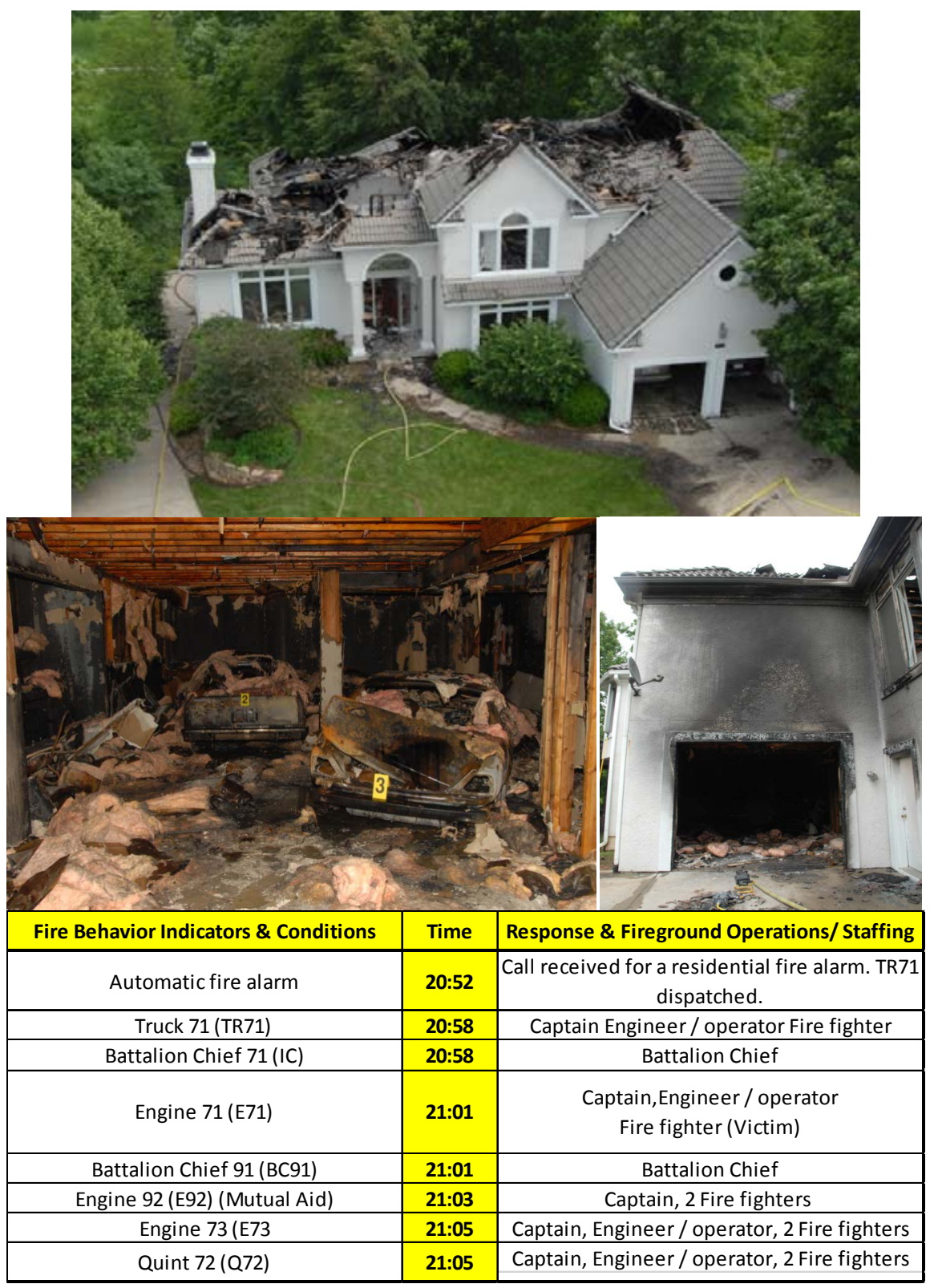

Figure 2. Effect of fire on a residential building without fire sprinkler system (Courtesy of the National Institute for Occupational Safety and Health (NIOSH) [20]).

caused the fire to spread. In such an incident, the use of fireproofing curtains or paints [22] [23] could prevent or slow down the spread of fire to roof and other areas of the building. The report shows unprotected openings in the building envelope caused the fire to spread. In such an incident, the use of fireproofing curtains or paints [22] [23] could prevent or slow down the spread of fire to roof and other areas of the building. In another fire incident, it was reported that the building envelope was damaged during a fire. This building was equipped with fire alarm system, which alerted the residents in a timely fashion thus leading to safe evacuation of the building. The home did have working smoke detectors. The fire department's quick response enabled firefighters to contain the fire just to the back of the structure and prevented further damage to the home. In this 
case, the use of fireproof paints [24] could have prevented or minimized further damage of building envelope.

One of the most significant current problems in fire safety of existing residential buildings is fire spread from openings (e.g., holes) and cracks in the walls. When a fire incident occurs, the generated flames tend to spread to other places where there is more oxygen. Therefore, the existing openings and cracks in the walls can encourage and help spread of the flames. Figure 3 shows a fire spread test on a wall with two different cover boxes for wall plug [25]. In this test, the left box was made of plastic and the right box was made of fireproof material. As Figure 3 shows, when the wall was exposed to fire, the left box melted and the flames could spread to the front side of the wall. On the other hand, the right box did not burn and blocked the fire spread.

Fire sprinklers systems using water are one of the most widely used fire extinguisher systems in residential buildings. The experience of residential fires has indicated that the fire sprinklers have acceptable performance to help life safety in such high temperature incidents [26]. Figure 4 shows a fire sprinkler head that is activated onfire. In this test, the sprinkler was indeed able to control the flames and to provide enough time for firefighters to arrive at the scene to extinguish the fire.

To further help better understanding of causes of typical fire incidents and their spread, a summary of several cases is included in Table 1, which shows an overview of five different reports about fire incidents in residential buildings. It is apparent from the table that most of the buildings reported have not been equipped with proper fire safety systems. The information in the table shows that the spread of fire and smoke from fire-source to other places is the main cause of increase in injury and damage in fire incidents. The most interesting point of the reports is that although using fire alarm device can play a vital role for safety of occupants, such devices need a complementary fire protection system.

\section{Fire Safety Techniques}

Fire hazard has always been a significant concern for building safety in comparison with other disasters (e.g., natural hazards). Although earthquakes and hurricanes as examples of more frequent natural hazards can turn to disasters for buildings, their frequency of occurrence and intensity levels depend on the regions

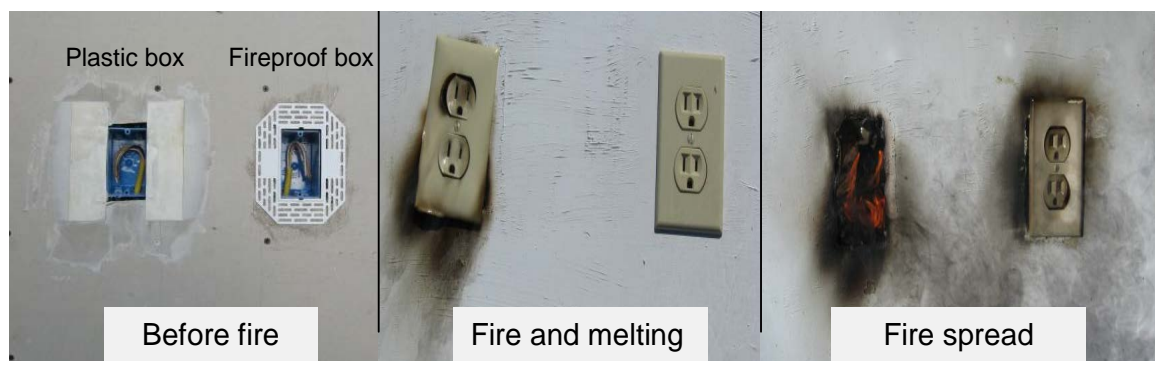

Figure 3. Stages of fire spread from wall plug (Courtesy of BPMI, Inc.

(http://www.bpmi-usa.com/) [25]). 


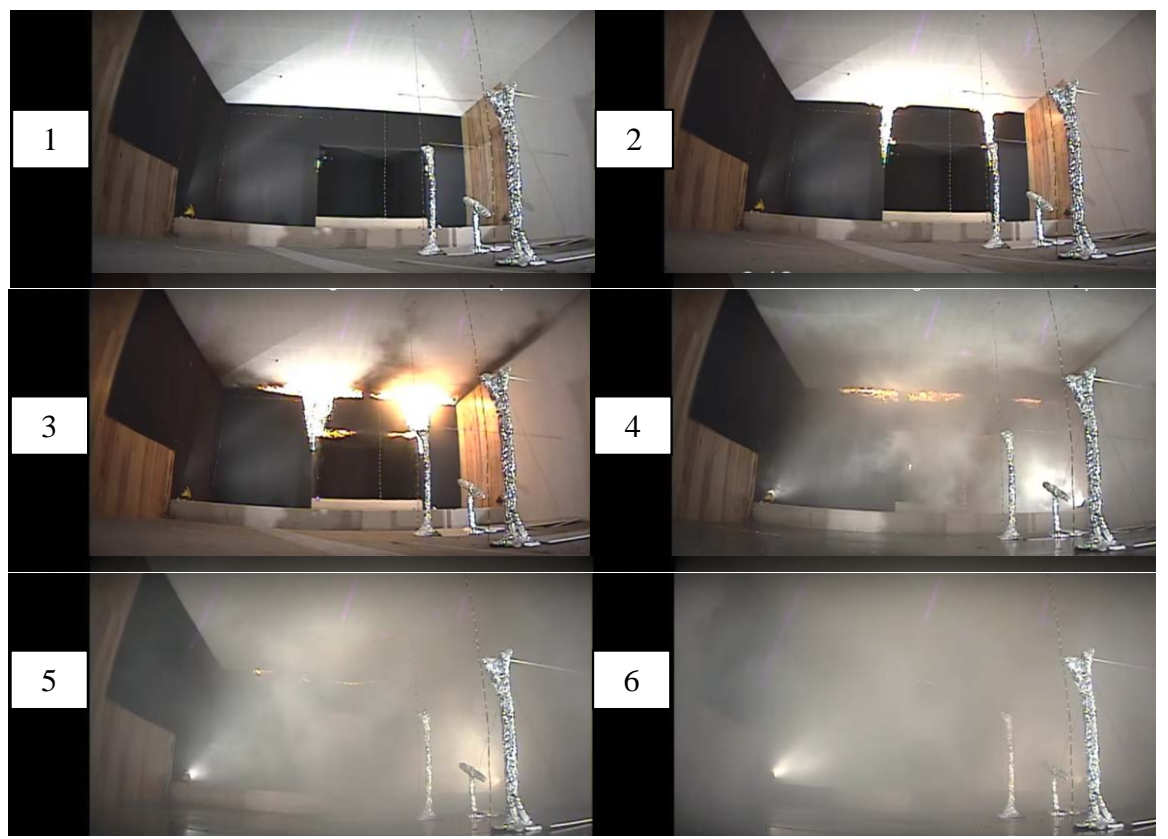

Figure 4. Activated sprinkler in a fire test to replicate the station nightclub fire (Courtesy of National Institute of Standards (NIST):

https://www.nist.gov/sites/default/files/documents/el/disasterstudies/ncst/Final_RI_Statio n_Nightclub_Status_12-3.pdf [27]).

Table 1. Sample of past fire incidents and test in buildings.

\begin{tabular}{|c|c|c|c|c|}
\hline Fire report & Damage and injury & Reason of damage & $\begin{array}{c}\text { Existing Fire } \\
\text { protection system }\end{array}$ & Fire safety problem \\
\hline $\begin{array}{l}\text { Fire incident involved a } 6000 \text { square foot } \\
\text { two-story single family residence with a } \\
\text { full basement that was built in } \\
\text { 1998-Kansas (NIOSH } 2011[20] \text { ) }\end{array}$ & $\begin{array}{l}1 \text { killed, roof collapse, } \\
\text { wooden walls and } \\
\text { doors }\end{array}$ & $\begin{array}{l}\text { Spread smoke and fire from } \\
\text { roof, open doors and corridors }\end{array}$ & Fire alarm & $\begin{array}{c}\text { lack of an adequate fire } \\
\text { sprinkler system and isolated } \\
\text { places against fire spread }\end{array}$ \\
\hline $\begin{array}{c}\text { Fire incident in a residential building in } \\
\text { Peekskill-Cortland, NY (Pappas } 2015 \\
[21])\end{array}$ & $\begin{array}{c}\text { Destruction of } \\
\text { building envelope }\end{array}$ & $\begin{array}{l}\text { Spread fire from open } \\
\text { windows to building envelope }\end{array}$ & non-equipped & $\begin{array}{c}\text { lack of fire sprinkler system or } \\
\text { fire proof paint on the building } \\
\text { envelope }\end{array}$ \\
\hline $\begin{array}{l}\text { A fire spread test from masonry walls } \\
\text { (Mulligan Products } 2015 \text { [25]) }\end{array}$ & $\begin{array}{l}\text { Melting plugs behind } \\
\text { of the wall }\end{array}$ & $\begin{array}{l}\text { Spread fire from small holes of } \\
\text { the plugs in the wall }\end{array}$ & non-equipped & lack of fireproof box for plugs \\
\hline $\begin{array}{l}\text { Fire in a residential building } \\
\text { (Hevern } 2011[26])\end{array}$ & Burning sofa & $\begin{array}{l}\text { Fire was controlled by } \\
\text { sprinkler top of the sofa }\end{array}$ & $\begin{array}{l}\text { Fire alarm and } \\
\text { sprinkler }\end{array}$ & $\begin{array}{c}\text { lack of isolated places against } \\
\text { smoke spread }\end{array}$ \\
\hline
\end{tabular}

where buildings are located. However, records of past fire incidents show that fire accidents may occur in any region and any building type, although more frequent in residential buildings [28] [29]. Therefore, if fire safety measures are not appropriately considered in design and maintenance of buildings, the result could be increased risk of building damage and tragedy. Performance of buildings has shown [30] [31] [32] that actual structural stiffness of buildings with structural steel framing members will be reduced due to fire, which will also affect load bearing capacity of heated members. The softening of structural mem- 
bers under heat can compromise the stability of whole building. Studies [33][39] have also found that during a fire, elevated temperature of members exposed to fire can induce large axial forces in restrained structural members due to thermal expansion. This phenomenon is thought to be the main cause of early building collapse during a fire.

For many years, the use of fire protection systems in buildings has been undervalued and largely misunderstood [16]. This was first realized when a number of real fires occurred in buildings. As one of the pioneers in fire research, John Carey designed a perforated pipe concept for fire protection systems in 1806 [40]. Three years later in 1809, William Cosgrove of London patented an improvement to the system that used $190^{\circ} \mathrm{F}$ rated fusible link actuators, an outside control valve, and a fire department connection [40]. Before 1990, fire safety projects dealing with thermal resistance of buildings mainly focused on manual systems such as fire hose reels, fire buckets and manual foam fire extinguishers. In more recent years, there has been an increasing interest in designing practical protection systems against fire. Some of these design methods recommend traditional protection systems for materials and devices, which vary depending on safety, size and economic justification of projects. The protection methods are divided into three sub-categories: 1) protection by mechanical systems such as fire sprinklers, 2) chemical flame retardants such as coating or isolating members by the use of fire resistance coating material and 3) structural mass resistance such as increase in size of members' sections or embedding members in concrete.

\subsection{Mechanical Systems}

While a variety of thermal protection systems have been suggested, fire sprinkler systems have always been ranked top. Fire sprinkler systems are one of the most widely used methods of mechanical solutions as a thermal protection system for buildings. A fire sprinkler works as an active fire-protection system. This system consists of a water supply and a piping system that provide the required pressure for spraying water by sprinklers on fire. The experience of residential fires indicates that fire sprinklers have acceptable performance for life safety at high temperatures [41]. Numerous studies have attempted to explain the performance of sprinklers at high temperature (fire) incidents [42] [43] [44] [45]. Zhou et al. [46] studied spray capability of "pendent" sprinklers. They used an imaging laser system to monitor the sprayed water drop size, density, volume and velocity. The test was carried out in two cases, near-field spray and far-field spray by pendent sprinkler. The results illustrated that in the near-field case, the density increases but the water drop size reduces. On the other hand, the far-field test displayed inverse result based on water spray density and drop size.

\subsubsection{Wet and Dry Pipe Fire Sprinkler Systems}

Wet pipe system is one of the most common methods among sprinkler systems, where water is always kept in the pipe system such that when sprinklers are ac- 
tivated, water is immediately sprayed onto fire. The advantages of the wet pipe fire sprinkler system can be considered to be reliability and simplicity. This system has minimum number of components and parts and thus low probability for malfunction [47]. The simplicity of a fire protection system is always significant in terms of system maintenance and providing required facilities. Therefore, wet pipe fire sprinkler systems require the least cost for installation, maintenance and also require less service time. Another advantage of this system is flexibility in modification since changes may include shutting down part or whole drain piping systems and water sources. The wet pipe sprinkler system needs minimum power to be restored. In most cases, sprinklers are restored by a simple repair or replacement of the unit. Perhaps the most serious disadvantage of this method is that wet pipe systems are not suited for sub-freezing environments. Furthermore, this system is not compatible for cases where piping systems are subjected to impact damage, since the impact force can lead to damage of pipes and subsequent water leakage.

In "dry pipe" sprinkler system, pipes are filled with air or nitrogen. In this method, the air is held in the pipe under control of a remote valve. The dry pipe valve prevents flow of water into the pipe until a fire occurs. The fire that heats the sprinkler triggers the system, which causes the pressurized air to escape. Next, the valve is released and water flows into the pipe, sprinkler heads and onto the fire. One of the significant advantages of the dry pipe sprinkler method is automatic fire protection system at low and freezing temperatures. The most suitable application of the dry pipe system at normal temperatures is in the following spaces or building types: unheated areas such as attics, and buildings such as warehouses and moisture-sensitive museums. It should be noted that any probable leaking in the wet pipe system may lead to physical damage. For example, in a library or museum, any water leak can potentially lead to significant or irreparable damage to collections due to excessive humidity.

One of the weak points of the dry pipe fire sprinkler system is its complicated setup and necessary maintenance in comparison with the wet pipe system. The dry pipe method needs extra control for air pressure in pipes and without correct monitoring of the pressurized air, this system can be less reliable than the wet pipe fire protection method. High expenses of installation and maintenance are another disadvantage of the dry pipe systems. In the dry pipe method, water spray on fire starts after 60 seconds from the time a sprinkler is activated. This delay may lead to extra damage and may lead to the need for more fire extinguishing actions.

\subsubsection{Victaulic Vortex ${ }^{\mathrm{TM}}$ Fire Suppression System}

In the Victaulic Vortex Fire Suppression System [45], combination of water and nitrogen is employed to extinguish fire. In this method, small drops of water absorb the rising temperature in the space resulting from fire and the amount of oxygen available around the fire area is reduced by nitrogen. In the Victaulic Vortex Fire Suppression System, water drops cause minimal wetting and nitrogen is not a toxic chemical agent. The Victaulic Vortex Fire Suppression is one 
of the modern available fire protection systems (Figure 5). In this fire protection system, combination of water and nitrogen can create a safe environment without any harm to human occupancy due to nitrogen, which is stored under pressure and atomizes water droplets to a sub-10 micron sizes. This size of water droplets can help cool and absorb the heat from a fire. In addition, the nitrogen starts to reduce the oxygen concentration in the air to below 16 percent, which is the minimum threshold to support fire. Lowering the oxygen content is not harmful for people in room/space, since the minimum/border oxygen level for human is 12 percent. The Victaulic Vortex Fire Suppression system can be used in museums, libraries, power facilities, automotive facilities, industrial facilities, data centers and mining facilities. The Victaulic Vortex Fire Suppressing System can be an effective fire-suppressant system with no toxic chemicals and flexible in design, while leaving limited moisture in the process. It needs a low-volume water supply and does not require an outside water source and additional piping. In addition, it can be used in a sealed partially ventilated space that does not require a fan test and can be rapidly reset after discharge. Additionally, this system is designed to work with appropriate outside alarm and detection systems. Figure 5 shows an application of the Victaulic Vortex Fire Suppression System.

\subsubsection{Pre-Action Fire Sprinkler System}

In the pre-action fire sprinkler system is similar to dry pipe method such that water is not typically contained inside the pipes. In this system, an electrically operated valve controls water as a pre-action valve. The valve operation is activated by flame, heat, or smoke detection. To extinguish fire by a pre-action method, two steps should be followed. First, fire detection devices must alarm a

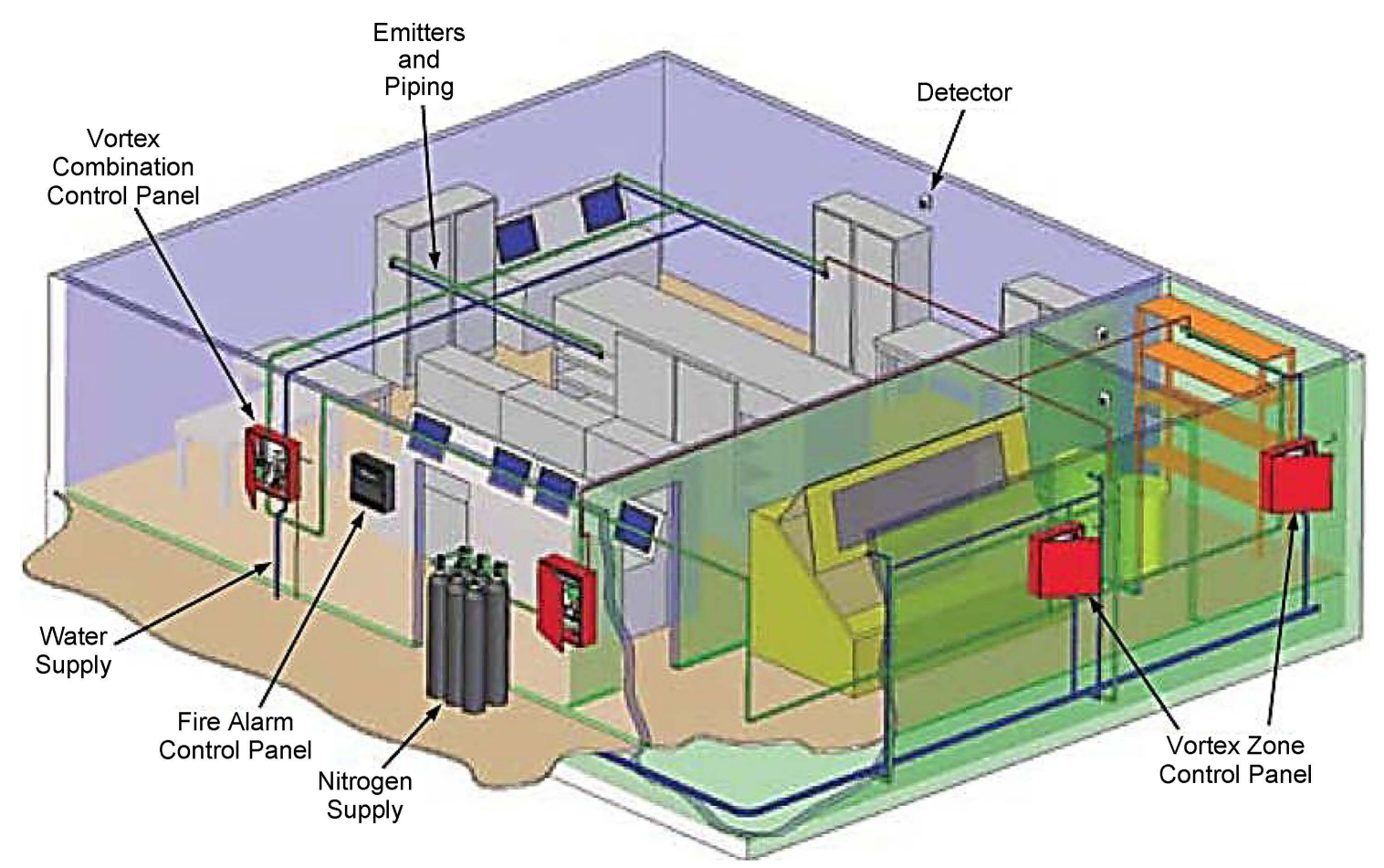

Figure 5. Application of the vortex fire suppression system (Courtesy of Victaulic Company [48]). 
developing fire; next, the pre-action valve is activated. In the first step, the detection system allows water to flow in the piping system, and in the next step, sprinklers start spraying water on fire. In some cases, the pre-action fire sprinkler can be combined with pressurized air or nitrogen that is added to the piping system. One of the most important advantages of pre-action systems is to extinguish fire by a dual system, which can provide an added step of protection against unintentional discharge. In other words, to spray water under dual action condition, the valve should be operating and sprinkler heads must be active. On the other hand, disadvantages of employing the pre-action fire sprinkler systems include overhead expenses for installation and maintenance, and modification difficulties in comparison with dry pipe method. For example, any change in the main system can also affect fire detection devices. This system can be used for high-hazard industrial and commercial applications, as well as sensitive or valuable article storage spaces such as archival vaults, fine art storage rooms, rare book libraries and computer centers.

\subsubsection{Deluge Fire Sprinkler System}

In the deluge fire sprinkler method [46], sprinklers are open and there is no pressurized air flowing into the pipes. This system is linked to a water source with a deluge valve such that the valve is operated by a fire alarm detection system. Generally, fire detection systems are installed near sprinklers. In this case, after detection of smoke or heat by fire safety devices, water discharges into the pipes and sprinkler heads. The deluge fire sprinkler systems are generally used in high hazard spaces to prevent spread of fire to other areas.

In the deluge fire system, all sprinkler heads are open, and after detection of fire, water discharges into the piping system that covers a large area for spray. This can be one of the main reasons for using this method in the high hazard areas. In this method, the deluge valve plays a key role in the whole system such that the valve should prevent water from flowing into the pipes before fire detection. In some of deluge fire sprinkler systems, water is mixed with foam. In this combination method, foam can provide a large containment layer on fire and help speed up extinguishing the fire. Figure 6 shows the deluge fire sprinkler systems with water and foam.
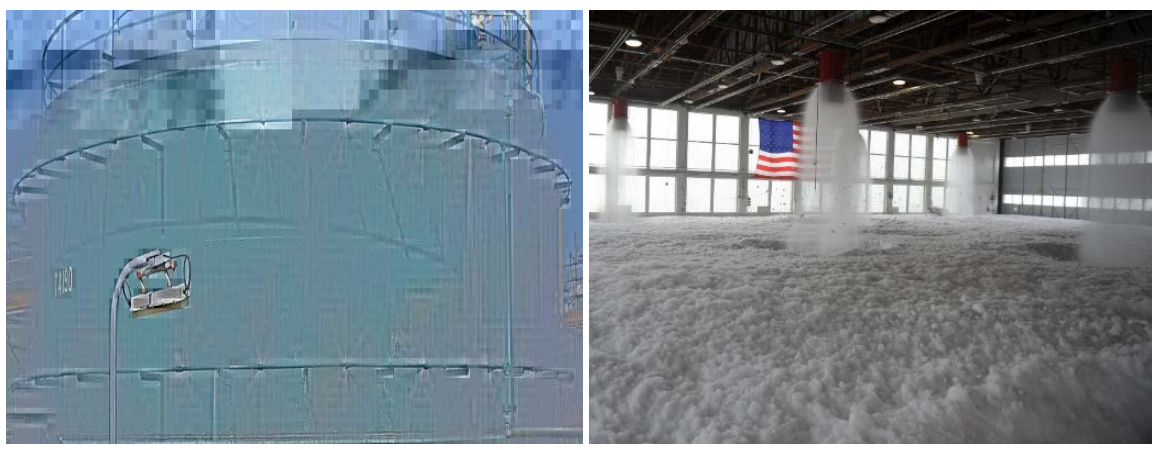

Figure 6. Deluge fire sprinkler system with water and foam (Courtesy of AusIMM - The Minerals Institute [49]). 


\subsection{Chemical and Coating Methods}

When a thermal collapse occurs in a building, surviving time plays a vital role based on safety standards. As a result, protection of structural members under high thermal conditions is essential to increase the surviving time. Softening of steel elements under intense fire heat has always been one of the main causes of early failure in steel members. In traditional thermal protection methods, chemical solutions have been suggested as a good way of increasing the surviving time. In this method, the main members such as steel columns and beams are coated with chemical thermal-proof materials (Figure 7). The chemical coating material has very low thermal conductivity compared to steel, which can protect steel members against early heating and potential early failures. The relationship between thermal conductivity and fire-proof materials has been widely investigated [50] [51] [52] [53]. Kodur and Shakya [54] investigated the behavior of steel members and thermal resistive materials at high temperature conditions. They examined three types of spray fire resistive material under high temperature loads to determine values of thermal conductivity, strain and specific heat. These tests were carried out at temperatures varying from $20^{\circ} \mathrm{C}$ to $1000^{\circ} \mathrm{C}$ to probe the effect of varied temperatures on coating materials and members. The results indicated that thermal conductivity and expansion behavior depend on temperature fluctuations. For example, when the applied temperatures vary between $20^{\circ} \mathrm{C}$ to $300^{\circ} \mathrm{C}$, thermal conductivity decreases, but it starts to increase at temperature range of $350^{\circ} \mathrm{C}$ to $700^{\circ} \mathrm{C}$. Moreover, this study illustrated that the specific heat of thermal resistive materials increases when temperature varies from $20^{\circ} \mathrm{C}$ to $100^{\circ} \mathrm{C}$, but it reduces at $300^{\circ} \mathrm{C}$ to $400^{\circ} \mathrm{C}$ range.

Fireproof paint is another chemical coating fire protection method, which provides a thin fire resistant and fire retardant layer on a wide range of interior building component surfaces. The use of this product can prevent spread of fire and help decrease high smoke levels. The experimental tests on this product indicate that when exposed to flame and fire, the fireproof paint swells as a result of thermal reaction and produces an insulating barrier that protects members

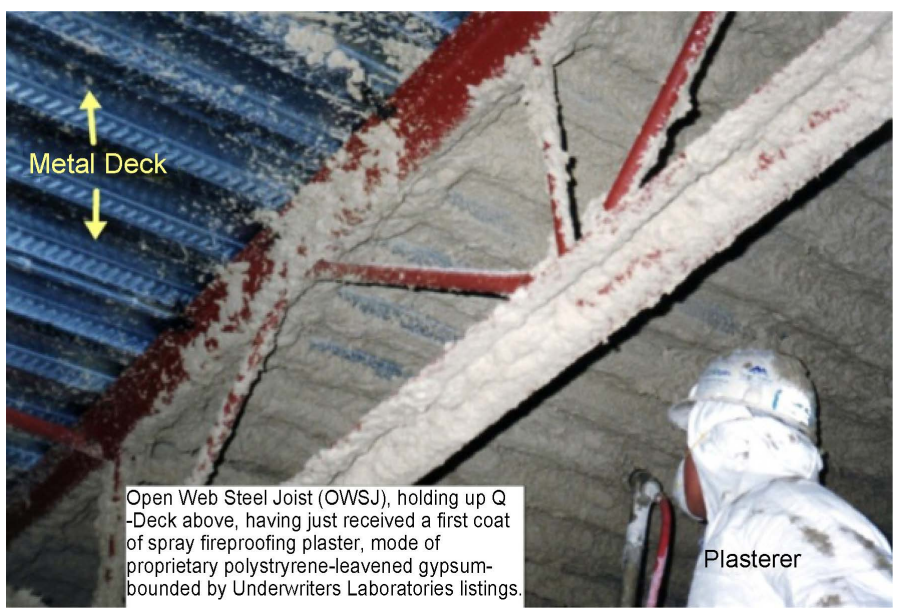

Figure 7. Spray chemical coating material on steel members (Courtesy of Ahering@cogeco.ca at English Wikipedia [55]). 
from intense heat. The fireproof paint also helps containing the level of flames, lead to confining flames in one space (room) and reducing generation of smoke. Fireproof paints have been used in a variety of residential, commercial and industrial buildings and structures. This product can be applied directly onto surfaces with alternative colors, which makes it a good option for protecting historical and old buildings against thermal effects. Figure 8 shows fireproof performance of small-scale buildings with conventional and fireproof paints.

The use of concrete coating for steel cross sections has always been one of the most widely used methods from the traditional solutions group. This method was studied by Landesmann [56] who discusses a steel-concrete structure exposed to thermal effects. In that research, the thermal performance of twelve beams with three different cross section coating details was investigated (Figure 9). First, a bare steel beam was exposed to elevated temperature (SB1); second, a steel beam with composite floor at top flange (CB1) was considered; and third, a steel beam with concrete coating (CB2) was studied. The thermal analysis of the three case studies indicated that the thermal load-bearing of the third case study (CB2) is higher than the other cases in terms of surviving time and that the second case (CB1) has good thermal performance as compared with the first case (SB1). The structural outcome of the study illustrated that the encased beam (CB2) has higher capacity for applied gravity loads compared with other cases. It is concluded that although the use of concrete coating can improve the thermal
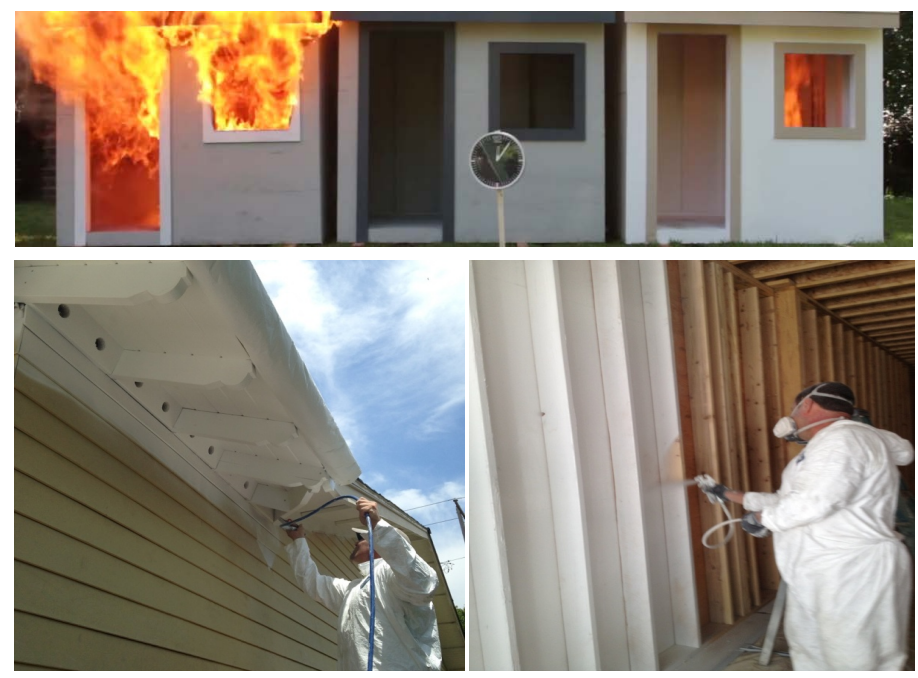

Figure 8. Performance of buildings with conventional and fireproof paints (Courtesy of Shield Industries, Inc. [24]).

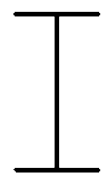

(a)SB1

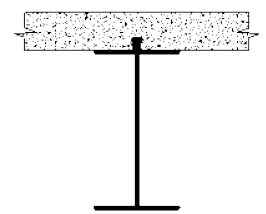

(b)CB1

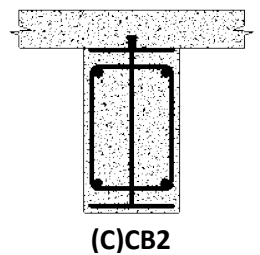

(C)CB2

Figure 9. (a) SB1 standard $\mathrm{W} 310 \times 31$ hot-rolled section, (b) CB1 simple composite beam and (c) CB2 beam with concrete coating [56]. 
performance of steel members, it also induces extra gravity loads that may result in less than desirable structural performance of the whole structure based on the overall load-bearing capacity and cost effectiveness.

\subsection{Fire Alarm Systems}

Fire alarm is a part of fire safety system that includes one or a number of devices that work together to detect fire, smoke, and carbon monoxide and warn people usually by fire alarm bell. The common audio alarms are: mechanical bells, horns and speakers. In many cases, the fire alarm system is connected to manual alarm switches installed in fire boxes. Fire reports show that in many cases people can sense fire earlier than such devices, so they need to activate the nearest manual fire alarm sounders or manual call points to warn others. The fire safety equipment follows standardized installation methods such as those by the National Fire Alarm Code. Fire alarms can be designed to be combined with other systems as a package; for example, emergency voice can be added to fire alarm systems, which are mentioned by NFPA as additional options for life safety systems in a panel. This type of smart fire alarm package can provide a wide range of programs to warn people and fire stations for rapid evacuation and fire extinguishing operation. The smart package plays a vital role in relation to controlling and managing fire safety systems in critical fire conditions. Perhaps simplified installation of the fire alarm package is one of the significant advantages of this system. With intelligent voice communication systems, facilities can provide flexible and networkable panels in an efficiently designed solution. The smart voice system provides comprehensive life safety options for buildings. The compact and scalable fire and emergency communication systems have industry-leading features such as hi-fi speakers and CD-quality sampling rates. All necessary components fit into a single enclosure, reducing the required wall space and making more efficient use of power sources. The concentrated components and remote diagnostics can also save in installation cost and service time. Figure 10 shows the fire alarm and emergency voice systems in a package.

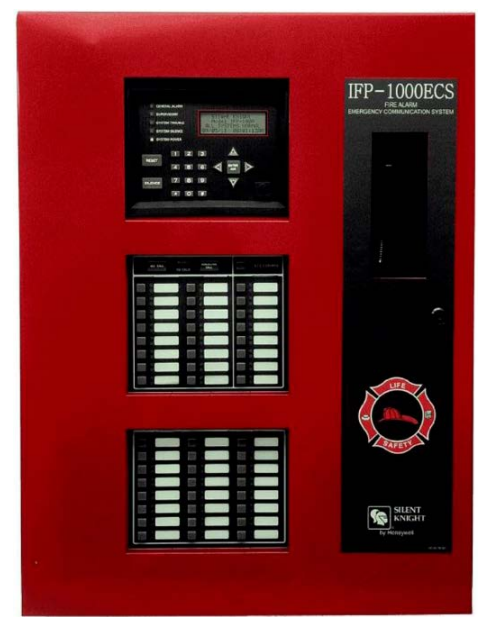

Figure 10. Fire alarm and emergency voice systems (Courtesy of Honeywell Security \& Fire [57]). 


\subsection{Fire-Resistant Wall (Gypsum Board)}

The past decade has seen the rapid development of building fire resistant materials. Fire resistant wall is one of the most widely used components, which are stable during a fire such that they can protect interior walls, e.g., wooden structure. Gypsum board is a type of fire resistant material that is widely used as a fire protection wall in buildings. Gypsum board (often called drywall) is the generic name for a group of sheet products that include primarily gypsum, non-combustible core and a paper surfacing on the face, back and long edges. Due to its non-combustible core, gypsum is different from other sheet building products such as fiberboards and hardboards. Known as an economical and reliable surfacing material, there has been an increasing interest in recent years in using gypsum board as a fire resistant cover for building members. Gypsum board is mainly made up of glass fiber and some chemical-based materials. Also, when it is used in walls in combination with other products such as foam or other insulation materials, a sound fire-resistant wall can be generated.

Thermal capacity of the fire-resistant board depends on thickness and material properties. The base chemical material of gypsum board is combined with water content of around 21 percent by weight. This water directly contributes as a fire stop layer to protect the board against penetration of fire. When gypsum board is exposed to intense heat, the water content slowly begins to evaporate and release as steam such that the generated steam layer itself would function as a fire barrier. This mechanism starts when moisture begins to evaporate and continues until all the evaporated moisture content is eliminated. The mechanism and process of evaporation and elimination of water in gypsum board is known as calcinations. Table 2 presents fire resistance rating of various partition walls.

\subsection{Firestop Materials}

Lack of an adequate method for control of fire spread in buildings has been a major problem in developing fire-extinguishing strategies for many years. Of course, the use of fire-resistant doors as a recommended traditional method has been a known solution method for this problem. However, since penetration of fire from gaps around pipes and wires ducts, holes and even cracks on walls or ceilings is an important cause for fire spread to adjacent spaces, a sealant type material is needed to address this problem. Accordingly, in recent years there has been an increasing interest for using fireproof plastic-based materials, referred to as "firestops" for filling and protecting gaps against penetration of fire [59] [60] [61]. The firestop technology offers a new fire protection method that seals joints and openings of walls or floors and works as a fire barrier in small openings and holes. Most firestop materials need to offer the flexibility needed to properly satisfy various applications in buildings. For example, firestop pillows [59] can fill open spaces around cables, in walls, floors, ceilings and pipe passes by discouraging the spread of fires, smoke and harmful gases. Cementitious mortar is another type of firestop materials, which is an economical, light-weight, Portland 
Table 2. Fire resistance rating of partition walls [58].

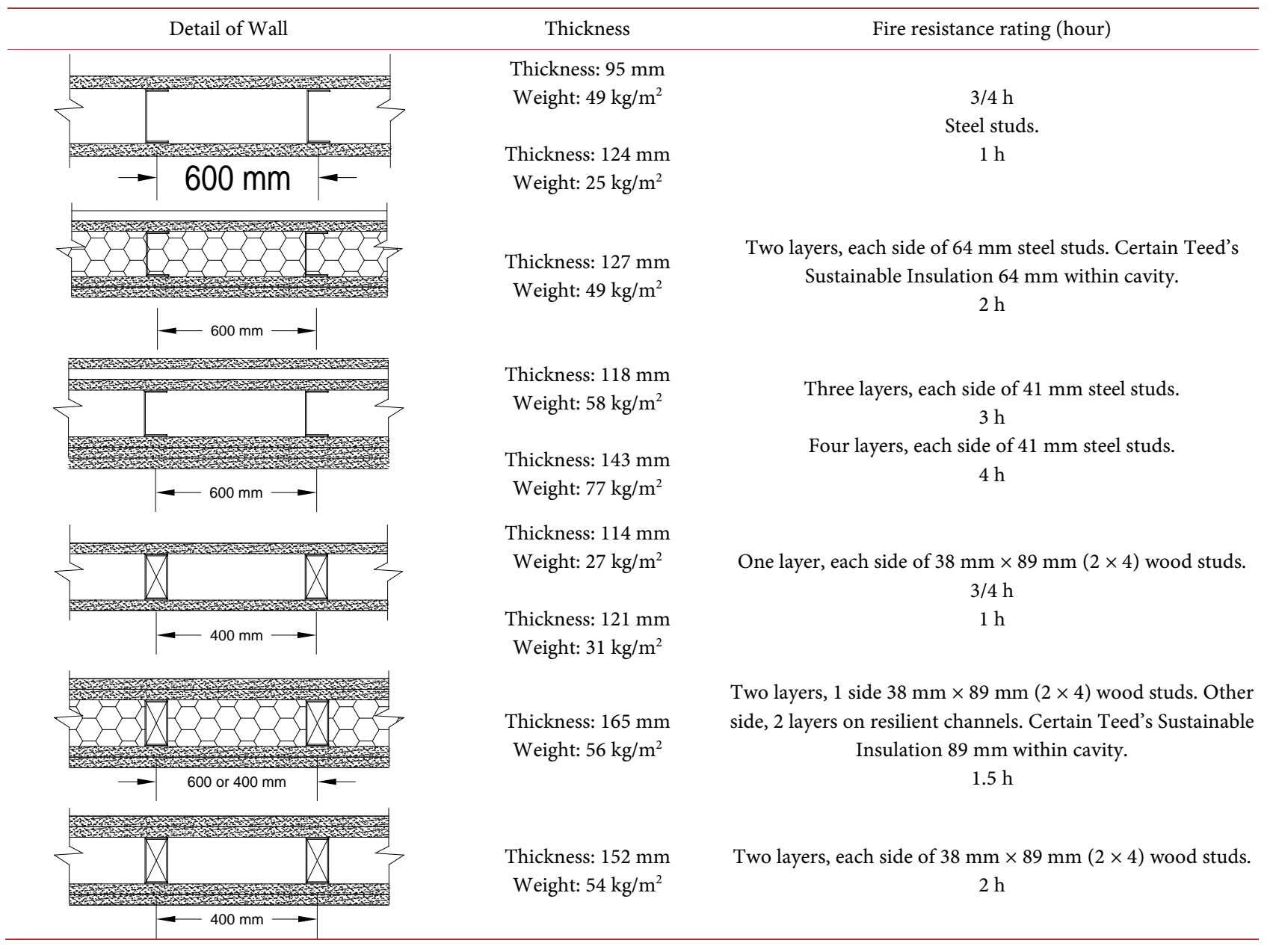

cement-based firestop product. This passive (non-intumescent) material utilizes a combination of heat sinking and insulating properties to provide an extremely high level of fire resistance. This mortar dries quickly and does not crack or spall due to freezing or changes in temperature. Firestop mineral wools, rubbers and firestop foams are other products of the family of firestops. The main applications of firestops include: junctions between fire-resistance rated wall or floor assemblies, around electrical and mechanical penetrations, unpenetrated openings (e.g., openings for future use), and head of walls. Figure 11 shows applications and temperature resistance rating of firestop materials.

\subsection{Fireproof Curtains}

Fireproof curtains are often more effective than a fire extinguisher in passive fire safety systems when we need to protect areas against fire spread. Fireproof curtains are made from fire resistant materials such as fiberglass or mineral wool [62] [63]. When a fire occurs, the fireproof curtain provides a fire resistant barrier against fire spread similar to a fireproof door or partition wall. While fire barrier function can be considered the first stage of its effectiveness, the second stage involves reduction of flow of oxygen to the affected area because of its 
function of confining the fire, which can then lead to extinguishing the fire similar to application of fire blankets. Therefore, this fire protection system has two mechanisms: first, confining fire within a space, and then reducing oxygen for easier and faster fire extinguishing. Fireproof curtains are employed for filling openings where fire may penetrate in order to prevent fire spreading to other parts of building or rooms. This protection system can be used in fire hazard areas to separate escape routes such as stairs, lifts or lobbies from other places. Developments in smart controlling of fire safety devices have influenced advancements on more recent product lines of this fire protection system such that the fireproof curtains can automatically connect to building fire alarm system. After detecting fire by fire-alarm the smart control-system sends a signal to control box of the fireproof curtains to open and work as a barrier against fire spread. Figure 12 shows application of the fireproof curtains in a building.

\section{Retrofitting Stages of Residential Buildings against Fire}

When an existing building is considered for (other than fire) upgrade changes, it is also advisable to consider possibility of adding new fire protection systems to satisfy new fire code requirements. Retrofit design of an existing building begins

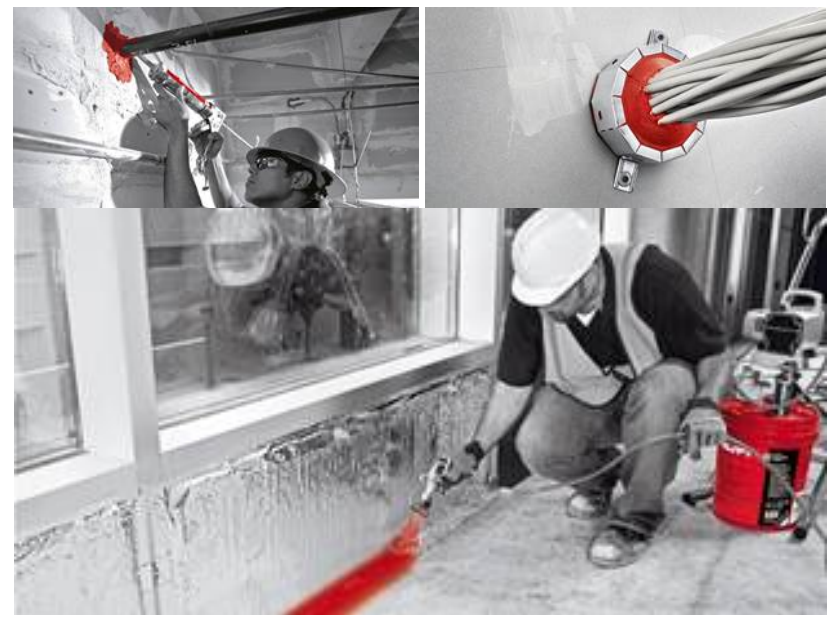

Figure 11. Application of firestops (Courtesy of Hilti https://www.us.hilti.com/content/hilti/W1/US/en/engineering/design-centers/firestop).
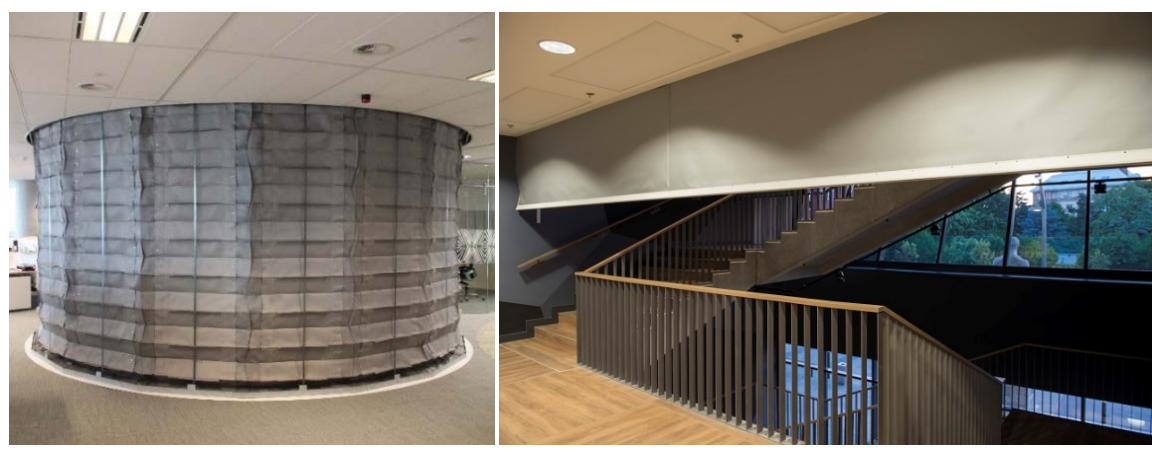

Figure 12. Separation of exit routes by fireproof curtain in a building (Courtesy of Greene Fire [62]). 
with a primary evaluation of current fire protection system. After the evaluation process, review of various fire protection systems appropriate for the building and fire codes is carried out and some options identified. Finally, from the list of viable alternatives, one or combination of protection systems are selected based on the budget and level of fire hazard protection required for the project. Advantages of fire retrofitting of existing buildings with deficient fire-safety systems include: 1) building code compliance, 2) decrease in potential fire-related damage and losses, 3) flexibility for changes in building, 4) improved life safety and 5) reduced property insurance premiums. Figure 13 shows a flowchart identifying various stages of retrofitting an existing residential building against fire. As the flowchart indicates, each building needs to be inspected in terms of fire safety criteria. The primary inspection can be separately carried out on structural and non-structural components. For designing an adequate retrofitting plan in residential buildings, three stages should be considered. In the first step, the potential fire areas such as mechanical room and kitchen should be identified to inspect fire extinguisher systems. In the second stage, the existing cracks and holes on the walls, floor and roof should be marked and filled by a proper fireproof (firestop) material. The aim of this stage is to separate and protect important spaces against fire spread. Therefore, in some cases the use of fireproof elements such as fireproof curtains and doors may be necessary to separate escape routes from other areas. In the last stage, the potential smoke and fire areas should be identified for installation smoke detectors and fire alarms. Figure 14 shows various alternatives for fire extinguisher systems, fire alarms devices, and fire stop materials. By use of the proposed flowcharts in Figure 13 and Figure 14, we can find an adequate retrofitting design for existing residential buildings to equip them against any probable fire incidents.

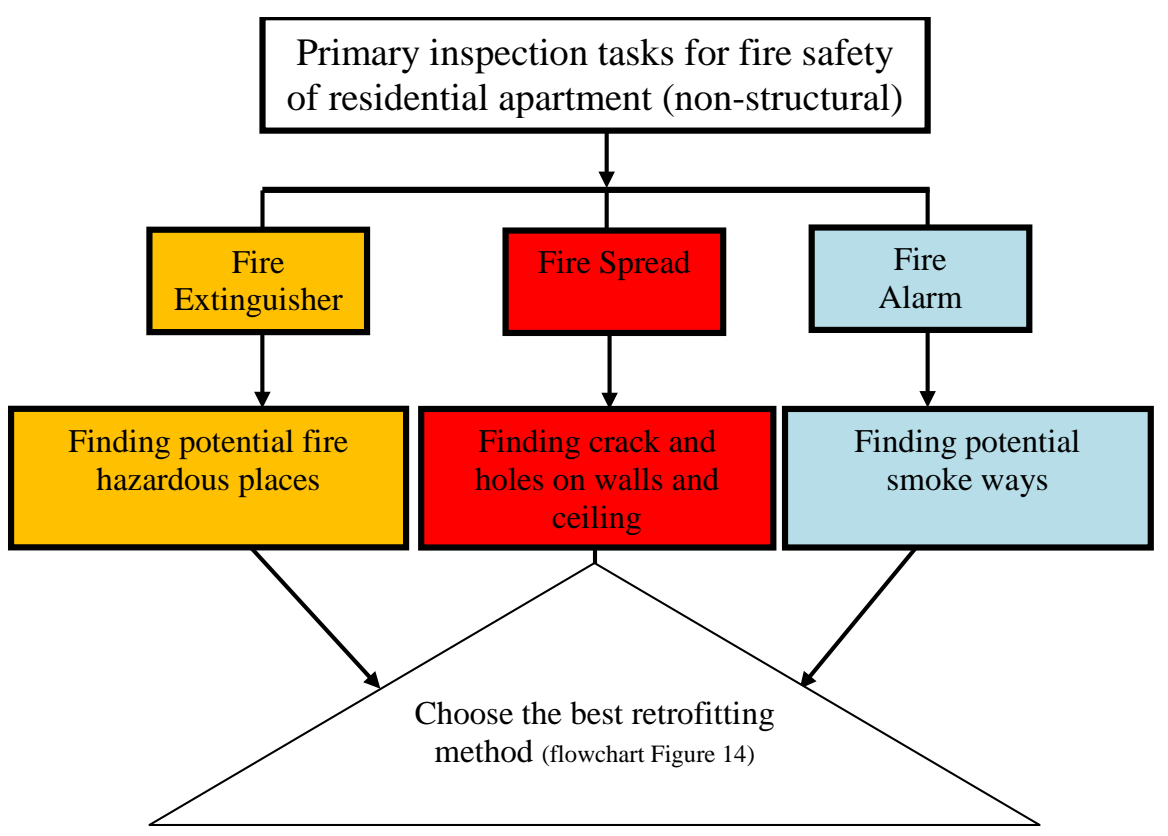

Figure 13. Primary inspection tasks for fire safety retrofitting of a building. 


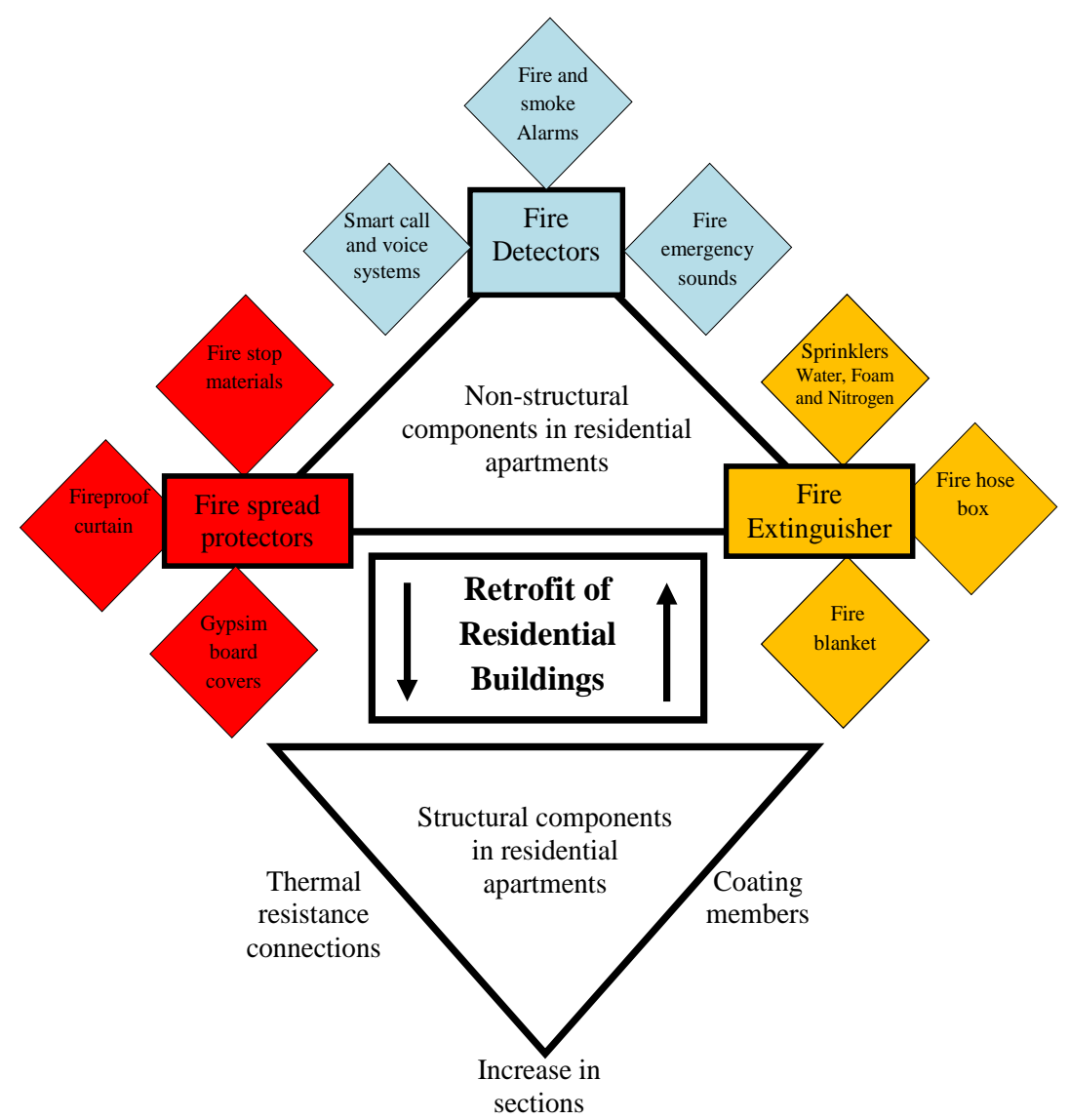

Figure 14. Overview of retrofitting in a residential building.

\section{Summary and Concluding Remarks}

A representative sample of relevant literature concerning fire incidents in buildings was reviewed to identify the main causes of fire spread in existing residential buildings. As older residential buildings constitute a considerable portion of existing residential building stock, and normally such buildings are more fire-safety deficient compared to newer buildings that have been constructed following more recent building codes, it is clear that a large number of such buildings need to be retrofitted to upgrade for an adequate fire safety system to satisfy the new fire codes. Review of the traditional and new retrofitting methods for fire safety of buildings in this report provides an overview of the technologies available. Information gathered from multiple sources and a variety of old and recent high-tech fire protection and retrofitting systems presented offer a state-of-the-art review of viable approaches that can be adopted for fire retrofit projects, including some of the advantages and disadvantages of fire protection devices and strategies.

Comparison of various features and attributes of different fire safety systems shows that each option has some strength and also some drawbacks. One can then conclude that the disadvantages of a solitary system for fire-retrofitting can be improved by using combination of several fire safety methods simultaneously. An important finding from this study is that proper inspection of fire alarm, fire 
extinguisher and fire spread control systems is a critical step in fire safety evaluation of an existing building that is considered for possible fire retrofitting.

\section{References}

[1] Karter, M.J. (2013) Fire Loss in the United States during 2012. NFPA.

[2] Yung, D. and Beck, R. (1995) Building Fire Safety Risk Analysis. SFPE Handbook of Fire Protection Engineering 1995.

[3] Wang, H. and Fan, W. (1997) Progress and Problems of Fire Protection in China. Fire Safety Journal, 28, 191-205.

[4] Zhong, M., Fan, W., Liu, T., Zhang, P., Wei, X. and Liao, G. (2004) China: Some Key Technologies and the Future Developments of Fire Safety Science. Safety Science, 42, 627-637.

[5] Xin, J. and Huang, C. (2013) Fire Risk Analysis of Residential Buildings Based on Scenario Clusters and Its Application in Fire Risk Management. Fire Safety Journal, $62,72-78$.

[6] Xin, J. and Huang, C.F. (2014) Fire Risk Assessment of Residential Buildings Based on Fire Statistics from China. Fire Technology, 50, 1147-1161.

https://doi.org/10.1007/s10694-013-0327-8

[7] Lo, S.M., Zhao, C., Liu, M. and Coping, A. (2008) A Simulation Model for Studying the Implementation of Performance-Based Fire Safety Design in Buildings. Automation in Construction, 17, 852-863.

[8] Lo, S.M. (1999) A Fire Safety Assessment System for Existing Buildings. Fire Technology, 35, 131-152. https://doi.org/10.1023/A:1015463821818

[9] Korhonen, T. and Hietaniemi, J. (2005) Fire Safety of Wooden Façades in Residential Suburb Multi-Storey Buildings. VTT Building and Transport.

[10] Oleszkiewicz, I. (1990) Fire Exposure to Exterior Walls and Flame Spread on Combustible Cladding. Fire Technology, 26, 357-375. https://doi.org/10.1007/BF01293079

[11] Kokkala, M., Mikkola, E., Immonen, M., Juutilainen, H., Manner, P. and Parker, W. (1997) Large-Scale Upward Flame Spread Tests on Wood Products. VTT TIEDOTTEITA.

[12] Madrzykowski, D., Bryner, N., Grosshandler, W. and Stroup, D. (2004) Fire Spread through a Room with Polyurethane Foam Covered Walls. National Institute of Standards and Technology, Gaithersurg, 5-7.

[13] Krasny, J., Parker, W. and Babrauskas, V. (2000) Fire Behavior of Upholstered Furniture and Mattresses. William Andrew.

[14] ASTM (2012) American Society for Testing and Materials in Standard Test Methods for Fire Tests of Building Construction and Materials. ASTM E119, West Conshohocken.

[15] EC3, Eurocode 3 (EC3), BS EN 1993-1-2 (2005) Design of Steel Structures, Part 1-2: General Rules-Structural Fire Design. British Standards Institution London, London.

[16] Engineering, S.F. (1991) Investigation of Broadgate Phase 8 Fire. The Steel Construction Institute.

[17] Wolski, A., Dembsey, N.A. and Meacham, B.J. (2000) Accommodating Perceptions of Risk in Performance-Based Building Fire Safety Code Development. Fire Safety Journal, 34, 297-309.

[18] Wong, L. and Lau, S. (2007) A Fire Safety Evaluation System for Prioritizing Fire 
Improvements in Old High-Rise Buildings in Hong Kong. Fire Technology, 43, 233-249. https://doi.org/10.1007/s10694-007-0014-8

[19] Shi, J., Ren, A. and Chen, C. (2009) Agent-Based Evacuation Model of Large Public Buildings under Fire Conditions. Automation in Construction, 18, 338-347.

[20] NIOSH (2011) Career Fire Fighter Dies While Conducting a Search in a Residential House Fire-Kansas. http://www.cdc.gov/niosh/fire/

[21] Pappas, J.J. (2015) Peekskill House Fire Set by Teen: News Report. http://patch.com/new-york/peekskill/peekskill-house-fire-set-teen-news-report

[22] Cui, Y.Q., Peng, Y.L. and Luo, C.L. (2014) Study on the Fire Protection Technologies for External Thermal Insulation System of the Buildings. Applied Mechanics and Materials, 638-640, 1646-1649.

[23] Hu, W.-C., Nurcholik, S.D., Lee, S.-K. and Lin, T.-H. (2016) Evaluations on Heat Resistance of Curtains with Water Film in a Fire. Journal of the Chinese Institute of Engineers, 39, 1-8. https://doi.org/10.1080/02533839.2016.1146092

[24] Weil, E.D. (2011) Fire-Protective and Flame-Retardant Coatings-A State-of-the-Art Review. Journal of Fire Sciences, 29, 259-296. https://doi.org/10.1177/0734904110395469

[25] Mulligan Products, Stages of Fire Spread from Wall Plug 2015.

[26] Hevern, E. (2011) Residential Sprinklers. http://www.semissourian.com/story/1705028.html

[27] Madrzykowski, D. (2004) The Station Nightclub Fire: Simulation of Fire and Smoke Movement in Laboratory Reconstruction.

[28] Emmons, H.W. (1983) The Calculation of a Fire in a Large Building. Journal of Heat Transfer, 105, 151-158. https://doi.org/10.1115/1.3245534

[29] Wu, N., Yang, R., Zhang, H. and Qiao, L. (2013) Decentralized Inverse Model for Estimating Building Fire Source Location and Intensity. Journal of Thermophysics and Heat Transfer, 27, 563-575. https://doi.org/10.2514/1.T3976

[30] Rotter, J., et al. (1999) Structural Performance of Redundant Structures under Local Fires. Proceedings of Interflam, 8th International Fire Science and Engineering Conference, Edinburgh, 5-7 June 1999, 12.

[31] Zahmatkesh, F., Osman, M., Talebi, E. and Kueh, A. (2014) Analytical Study of Slant End-Plate Connection Subjected to Elevated Temperatures. Steel and Composite Structures, 17, 47-67. https://doi.org/10.12989/scs.2014.17.1.047

[32] Zahmatkesh, F., Osman, M.H., Talebi, E. and Kueh, A.B.H. (2014) Direct Stiffness Model of Slant Connection under Thermal and Non-Symmetric Gravity Load. Journal of Constructional Steel Research, 102, 24-43.

[33] Liu, T.C.H. (1999) Fire Resistance of Unprotected Steel Beams with Moment Connections. Journal of Constructional Steel Research, 51, 61-77.

[34] Rodrigues, J.P.C., Cabrita Neves, I. and Valente, J.C. (2000) Experimental Research on the Critical Temperature of Compressed Steel Elements with Restrained Thermal Elongation. Fire Safety Journal, 35, 77-98.

[35] Yin, Y.Z. and Wang, Y.C. (2004) A Numerical Study of Large Deflection Behaviour of Restrained Steel Beams at Elevated Temperatures. Journal of Constructional Steel Research, 60, 1029-1047.

[36] Wong, M.B. (2005) Modelling of Axial Restraints for Limiting Temperature Calculation of Steel Members in Fire. Journal of Constructional Steel Research, 61, 675687.

[37] Mourão, H.D.R. and Silva, V.P.E. (2007) On the Behaviour of Single-Span Steel 
Beams under Uniform Heating. Journal of the Brazilian Society of Mechanical Sciences and Engineering, 29, 115-122. https://doi.org/10.1590/S1678-58782007000100015

[38] Li, G.-Q. and Guo, S.-X. (2008) Experiment on Restrained Steel Beams Subjected to Heating and Cooling. Journal of Constructional Steel Research, 64, 268-274.

[39] Pi, Y.L., Bradford, M.A. and Qu, W.L. (2011) Extremal Thermoelastic Buckling Analysis of Fixed Slender Beams. Procedia Engineering, 14, 256-263.

[40] Jain, V.K. (2007) Fire Safety in Buildings. Taylor \& Francis, Abingdon-on-Thames.

[41] Moinuddin, K. and Thomas, I. (2014) Reliability of Sprinkler System in Australian High Rise Office Buildings. Fire Safety Journal, 63, 52-68.

[42] Li, K., Hu, L., Huo, R., Li, Y., Chen, Z., Li, S. and Sun, X. (2009) A Mathematical Model on Interaction of Smoke Layer with Sprinkler Spray. Fire Safety Journal, 44, 96-105.

[43] Lai, C.-M., Chen, K.-J., Chen, C.-J., Tzeng, C.-T. and Lin, T.-H. (2010) Influence of Fire Ignition Locations on the Actuation of Smoke Detectors and Wet-Type Sprinklers in a Furnished Office. Building and Environment, 45, 1448-1457.

[44] Butry, D.T. (2012) Comparing the Performance of Residential Fire Sprinklers with Other Life-Safety Technologies. Accident Analysis \& Prevention, 48, 480-494.

[45] Zhang, C. and Chow, W. (2013) Numerical Studies on the Interaction of Sprinkler and Smoke Layer. Procedia Engineering, 62, 453-462.

[46] Zhou, X., D’Aniello, S.P. and Yu, H.-Z. (2012) Spray Characterization Measurements of a Pendent Fire Sprinkler. Fire Safety Journal, 54, 36-48.

[47] Hall, J.R. (2007) US Experience with Sprinklers and Other Automatic Fire Extinguishing Equipment. National Fire Protection Association, Quincy.

[48] Reilly, B. (2008) The Victaulic "Vortex" Multiple Agent Fire Extinguishing System. The 2008 Spring National Meeting.

[49] Bilson, M., Purchase, A. and Stacey, C. (2008) Deluge System Operating Effectiveness in Road Tunnels and Impacts on Operating Policy. Proceedings 13 th Australian Tunnelling Conference, Melbourne.

[50] Bentz, D.P., Prasad, K.R. and Yang, J.C. (2006) Towards a Methodology for the Characterization of Fire Resistive Materials with Respect to Thermal Performance Models. Fire and Materials, 30, 311-321. https://doi.org/10.1002/fam.916

[51] Bentz, D.P. and Prasad, K. (2007) Thermal Performance of Fire Resistive Materials: I. Characterization with Respect to Thermal Performance Models. US Department of Commerce, Technology Administration, National Institute of Standards and Technology.

[52] Kwak, Y.K., Pessiki, S., Kwon, K. and Kim, H.-K. (2008) Fire Behavior of Steel Columns Encased by Damaged Spray-Applied Fire Resistive Material. Architectural Research, 10, 1-11.

[53] Arablouei, A. and Kodur, V. (2014) A Fracture Mechanics-Based Approach for Quantifying Delamination of Spray-Applied Fire-Resistive Insulation from Steel Moment-Resisting Frame Subjected to Seismic Loading. Engineering Fracture Mechanics, 121, 67-86.

[54] Kodur, V.K.R. and Shakya, A.M. (2013) Effect of Temperature on Thermal Properties of Spray Applied Fire Resistive Materials. Fire Safety Journal, 61, 314-323.

[55] Ahering (2006) Spray Chemical Coating Material on Steel. https://commons.wikimedia.org/wiki/File:Owsj_deck_fireproofing.jpg

[56] Landesmann, A. (2012) Refined Plastic-Hinge Model for Analysis of Steel-Concrete 
Structures Exposed to Fire. Journal of Constructional Steel Research, 71, 202-209.

[57] Knight, S. (2015) Fire Alarm and Emergency Voice Systems. https://www.silentknight.com

[58] CertainTeed, C. (2012) Gypsum Board Systems Manual. CertainTeed, 1-52.

[59] Choices, F. (2004) A Head Start on Firestopping. Environment of Care News, 7.

[60] Hilti, C. (2011) 642 Fire Stop Jacket Product Information.

[61] Firestopping, A.E.S. (2000) Single Component Silicone Elastomeric Compound and Compatible Silicone Sealant. 1. Manufacturers. A/D Fire Protection Systems Inc., 3M Fire Protection Products, Hilti, Inc., Specified Technologies, Inc., Substitutions: See Section, Vol. 1, 60.

www.adfire.com

www.3m.com/firestop

www.us.hilti.com

www.stifirestop.com

[62] Coopers (2015) http://www.coopersfire.com.au

[63] Yamada, T., Yanai, E. and Nasa, H. (2000) Study of Full-Scale Flammability Tests of Flame-Retardant and Non Flame-Retardant Curtains. Fire Safety Science, 4, $463-$ 474.

Submit or recommend next manuscript to SCIRP and we will provide best service for you:

Accepting pre-submission inquiries through Email, Facebook, LinkedIn, Twitter, etc. A wide selection of journals (inclusive of 9 subjects, more than 200 journals) Providing 24-hour high-quality service User-friendly online submission system Fair and swift peer-review system Efficient typesetting and proofreading procedure Display of the result of downloads and visits, as well as the number of cited articles Maximum dissemination of your research work

Submit your manuscript at: http://papersubmission.scirp.org/

Or contact ojce@scirp.org 